\title{
Avaliação das características termais superficiais do município de Jacareí (SP) por meio de geotecnologias
}

\author{
Evaluation of the thermal surface characteristics of the municipality of Jacareí, SP by means \\ of geotechnologies
}

\author{
Rodrigo da Cunha Pacheco \\ Doutor em Geografia e professor do Instituto Federal de São Paulo, Brasil \\ rodrigo.pacheco@ifsp.edu.br
}

\section{Resumo}

Este artigo visa demostrar, por meio de um estudo de caso, que diferentes usos da terra implicam em distintas temperaturas superficiais que podem ser avaliadas por meio do uso das geotecnologias. Assim, toma o município de Jacareí como área de estudo e utiliza de SIGs, cenas Landsat-8 e Cbers4 para efetuar a presente proposta. Os usos da terra de Jacareí podem ser distinguidos em quatro grandes tipos: corpos de água, vegetação herbácea (frequentemente usadas como pastagens), vegetação arbórea (incluindo plantações de eucaliptos) e áreas urbanas (com enclaves de vegetação). Demonstrou-se, de forma inequívoca, que superfícies vegetais arbóreas densas apresentam temperaturas de superfície inferiores às superfícies urbanas; assim, núcleos urbanos rodeados por cobertura vegetal arbórea geram pontos com superfícies relativamente mais quentes (as ilhas de calor superficiais), enquanto "ilhas vegetadas" em áreas urbanas geram regiões relativamente mais frias (ilhas de amenização das temperaturas superficiais). Isto indica que centros urbanos bastante arborizados podem favorecer melhor conforto térmico para a sua população e, consequentemente, melhor qualidade de vida. No caso do município de Jacareí, que está em franco processo de crescimento demográfico e urbano, indica-se a promoção de políticas públicas de arborização das suas áreas urbanas para que seus habitantes vivenciem em áreas com melhor qualidade ambiental.

Palavras-chave: temperaturas, uso da terra, sensoriamento remoto, geoprocessamento.

\begin{abstract}
This article seeks to demonstrate, through a case study, that different land uses imply different superficial temperatures, which can be evaluated with geotechnologies. Thus, it takes the municipality of Jacareí as the area of study and uses GIS, Landsat- 8 and Cbers- 4 scenes to execute this proposal. The land uses of Jacareí can be distinguished into four major types: water bodies, herbaceous vegetation (often used as pastures), arboreal vegetation (including eucalyptus plantations) and urban areas (with vegetation enclaves). It has been unequivocally demonstrated that dense arboreal vegetation surfaces have lower surface temperatures than urban surfaces; so, urban centres surrounded by arboreal vegetation cover generate spots with relatively warmer surfaces (the surface heat islands). In contrast "vegetated islands" in urban areas generate relatively colder regions (softening islands of surface temperatures). This indicates that fairly wooded urban centres can favour better thermal comfort for their population and, consequently, a better quality of life. In the case of the municipality of Jacareí, which is in rapid demographic and urban growth, the promotion of public policies to afforest its urban areas is indicated so that its inhabitants can live in areas with better environmental quality.
\end{abstract}

Keywords: temperatures, land use, remote sensing, geoprocessing. 


\section{INTRODUÇÃO}

O uso de geotecnologias para estudos ambientais se tornou uma prática consolidada na atualidade devido aos grandes ganhos de conhecimento e produtividade que elas permitem. Tais estudos, por sua vez, possibilitam a compreensão dos geossistemas em seus mais variados aspectos (morfológicos e dinâmicos), bem como em distintas escalas espaciais. Eles são de fundamental importância para o planejamento das intervenções antrópicas sobre o meio e, consequentemente, para a produção de um espaço que permita o desenvolvimento da vida social com a devida qualidade ambiental, que no Brasil, se apresenta como direito constitucional. Reza o artigo 225 da referida norma: "todos têm direito ao meio ambiente ecologicamente equilibrado, bem de uso comum do povo e essencial à sadia qualidade de vida [...]” (BRASIL, 1988).

Nesse contexto de preocupação com a qualidade ambiental, não somente no Brasil, mas em todo cenário internacional, é relevante constatar que um dos aspectos passíveis de ser abordado por meio do uso das geotecnologias é a caracterização da variação da temperatura superficial a partir dos diferentes usos da terra. Tal temática tem sido muito abordada na literatura científica, principalmente na investigação das diferenças térmicas superficiais relacionadas ao ambiente urbano, que acabam configurando o que pode ser denominado de ilha de calor de superfície urbana - surface urban heat island (VOOGT; OKE, 2003).

Dessa forma, este artigo tem como objetivo apresentar um estudo de caso, no qual se utiliza de geotecnologias para diagnosticar a configuração espacial termal de superfície do município de Jacareí, Estado de São Paulo (Figura 1), buscando estabelecer relações com os macrotipos de uso da terra. Em termos mais específicos, este estudo se utiliza do sensoriamento remoto e do geoprocessamento, os quais fazem parte de um conjunto mais amplo de geotecnologias (ZAIDAN, 2017, p.198). O sensoriamento remoto pode ser definido como: "a tecnologia que permite a aquisição de informações sobre objetos sem contato físico com eles" (NOVO, 1989, p.1); assim, cabe considerar que as tecnologias atuais permitem o uso de vários meios remotos de aquisição de informações da superfície terrestre, tais como aviões, drones e satélites. Com relação ao geoprocessamento, tem-se que é: “o conjunto de técnicas e métodos teóricos e computacionais relacionados com a coleta, entrada, armazenamento, tratamento e processamento de dados, a fim de gerar novos dados e ou informações espaciais ou georreferenciadas” (ZAIDAN, 2017, p.198). 


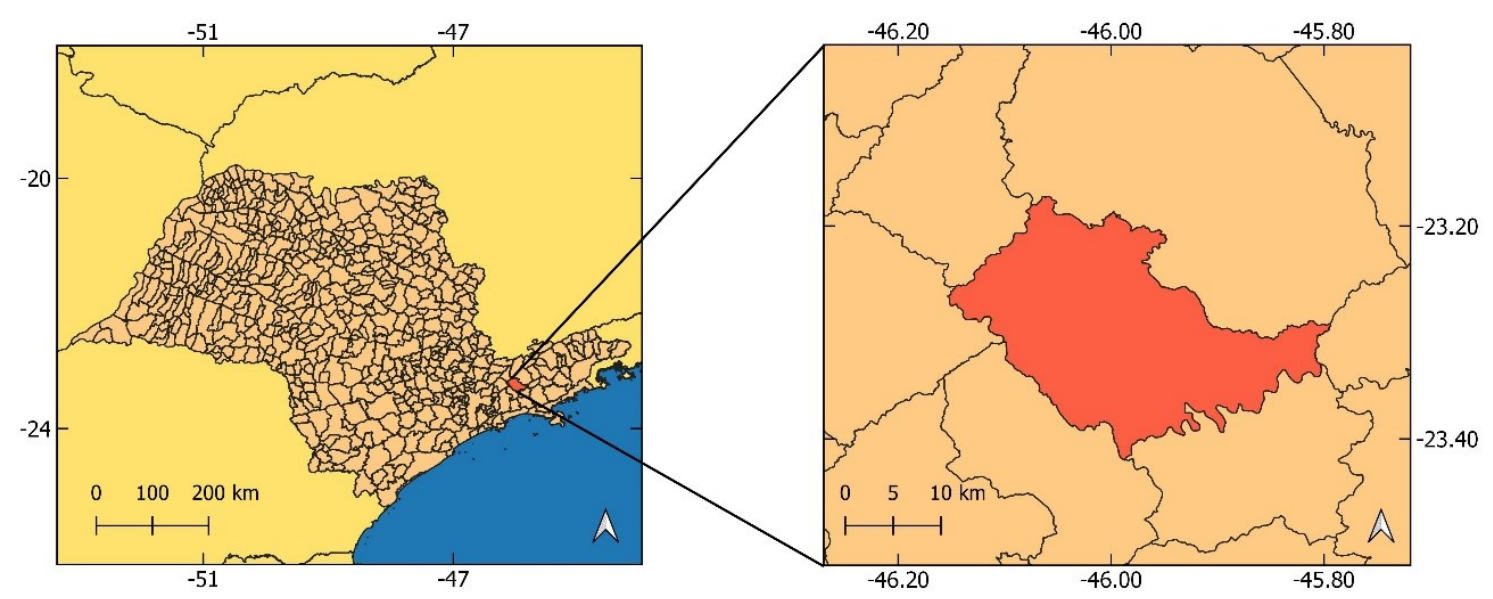

Figura 1 - Localização do Município de Jacareí no Estado de São Paulo.

Fonte: elaboração do autor a partir de dados vetoriais de IBGE (2019).

Esta pesquisa se justifica na medida em que gera produtos cartográficos e análises que permitem compreender uma das facetas ambientais do município de Jacareí de forma atualizada. A busca por informações sobre padrões térmicos correlacionados com o uso da terra não obteve sucesso em encontrar estudos prévios para o município, embora exista trabalho sobre o uso da terra e outros parâmetros ambientais (SILVA, 2002). As conclusões aqui apresentadas permitem aos atores sociais e gestores públicos do município refletirem sobre a produção de um espaço geográfico ambientalmente sadio para a sua população, levando em consideração os impactos dos diferentes usos da terra no conforto térmico, o que traz ganho potencial não somente no campo teórico e científico, mas também na esfera prática de aplicação do conhecimento geográfico, para fins do planejamento urbano municipal, por exemplo.

\section{MATERIAIS, METODOLOGIA E PROCEDIMENTOS OPERACIONAIS}

Foram utilizados como materiais específicos para o desenvolvimento deste estudo: I) Softwares de SIG (Sistemas de Informações Geográficas) - Qgis 3.10.10 e SAGA 7.6.3; II) cena Landsat-8, fornecida pelo USGS, com a área do município de Jacareí, referente ao dia 06/10/2020, horário aproximado de 13:04; III) duas cenas pancromáticas de 5 metros de resolução espacial do Cbers-4 para composição do mosaico da área do município, referentes aos dias 08/07/2018 e 24/09/2018 e fornecidas pelo INPE. IV) arquivos no formato shape, do Estado de São Paulo e seus municípios, disponibilizados pelo IBGE (2019).

A metodologia adotada foi a do levantamento de dados sobre as temperaturas de superfícies estimadas, bem como sobre o uso da terra por meio do sensoriamento remoto e do geoprocessamento, mediante o uso de técnicas e procedimentos operacionais específicos. A metodologia pode ser descrita como constando das etapas de: I) coleta de materiais e informações; II) processamento de 
dados; III) análise e sintetização das informações. Não obstante, a metodologia não foi aplicada de forma tão linear, tendo sido necessário, por vezes, retroagir nas etapas para então seguir novamente.

Os procedimentos técnicos e operacionais mais específicos foram: I) obtenção da cena Landsat-8; II) seleção da banda 10 (termal); III) utilização do limite municipal vetorial fornecido pelo IBGE para recorte da imagem da banda 10; IV) conversão dos números digitais em níveis de cinza para valores de temperatura de superfície, em graus Celsius, por meio do algoritmo apresentado na equação 1; V) reclassificação das temperaturas de superfície para 6 classes, com os intervalos apresentados na legenda da figura 4; VI) recorte das bandas 2,3 e 5 do Satélite Landsat-8, conforme o limite municipal, reamostragem para a resolução espacial de $15 \mathrm{~m}$, por meio do uso da imagem pancromática (banda 8) e elaboração de composição colorida falsa-cor R5G3B2, apresentada no mapa 2; VII) obtenção das cenas pancromática do Cbers-4; VIII) utilização do limite municipal para recorte das cenas pancromáticas; IX) produção do mosaico pancromático do município de Jacareí; X) formatação das cores, sobreposições de camadas e geração de mapas e imagens para análises; XI) geração de mapa de uso da terra por meio de classificação supervisionada, utilizando-se o método Winner takes all (tendo sido selecionados os seguintes métodos para comparação e julgamento dentro deste algoritmo: Binary Encoding, Parallelepiped, Minimum Distance, Mahalanobis Distance; Maximum Likelihood; Spectral Angle Mapping); XII) análise das variações de temperatura aparente conforme os tipos de uso da terra do município de Jacareí, auxiliada pela identificação de alvos no mosaico pancromático do Cbers-4; XIII) escolha de duas áreas representativas da influência dos tipos de uso da terra sobre a temperatura superficial para análise mais específica. É preciso salientar que todas as cenas e mapas foram padronizados para o sistema de referência espacial SIRGAS 2000 UTM $23 \mathrm{~S}$.

Quanto à forma de conversão dos níveis de cinza do sensor TIRS do Landsat-8 para temperatura de superfície em graus celsius, Coelho e Correa (2013) fizeram uma exposição completa, a qual foi aqui aplicada por meio do uso da equação 1 (TC na fórmula seria a temperatura em graus célsius).

$$
\mathrm{TC}=(1321.08 / \operatorname{Ln}(774.89 /(3.3420 \mathrm{E}-04 * \text { “banda10.tif” }+0.10000)+1))-273.15
$$

Uma observação importante que resta ser feita é a de que, pelo fato de a relação espacial dos valores dos pixels entre as distintas zonas da área em questão ser mais importante para este estudo do que a exata temperatura de superfície, a correção atmosférica não se apresentou como imprescindível, partindo-se da hipótese de que toda a área estaria sob um mesmo efeito geral da atmosfera; assim, sua não aplicação não comprometeu a avaliação mais importante sobre o comportamento dos padrões 
espaciais de temperatura térmica em relação aos tipos de uso da terra (as temperaturas, porém, são aproximadas).

A metodologia proposta é adequada para uma compreensão geral do comportamento termal superficial do município em relação aos usos da terra, especialmente ao se contrapor os dados empíricos obtidos do processamento das imagens de sensoriamento remoto com o conhecimento teórico referente à temática; todavia, é preciso reconhecer que há aqui uma limitação ao se utilizar de dados de apenas uma data específica, pois uma abordagem multitemporal permitiria confirmar as tendências das configuração espaciais térmicas diagnosticadas, algo que futuras pesquisas poderão verificar.

\section{ALGUMAS CONSIDERAÇÕES PRELIMINARES}

O uso de sensores remotos passivos multiespectrais do tipo imageadores, transportados por meios orbitais, como aqueles presentes no Landsat-8, possibilita a aquisição periódica de dados sobre a reflectância e emissão de energia da superfície terrestre. Sensores passivos são aqueles que somente registram a energia emitida/refletida por determinados alvos; eles são imageadores quando o registro é feito na forma de imagens (FITZ, 2008). A propriedade de se constituir em sensor multiespectral está relacionada com o conceito de resolução espectral, isto é, a capacidade que determinado sensor possui em fazer múltiplos registros de dados, conforme faixas delimitadas do espectro eletromagnético, as quais formam suas bandas espectrais (JESEN, 2009).

Diferentes objetos superficiais possuem distintas assinaturas (comportamentos) espectrais registradas pelos sensores, o que permite uma análise de características presentes nesses elementos, entre as quais, a temperatura superficial aparente. A faixa termal do espectro eletromagnético (ondas de 3.000 a 14.000 nanômetros de comprimento) captada pelos sensores, em janelas atmosféricas específicas, possui uma peculiaridade em relação à faixa do visível, pois todos os objetos acima do 0 grau absoluto $\left(-273,16^{\circ} \mathrm{C}\right)$ emitem energia na frequência termal, a qual pode ser registradas pelos sensores apropriados (JESEN, 2009); isso é interessante para o estudo dos elementos da paisagem, pois:

Os vários componentes da paisagem, tais como vegetação, solo, rocha, água, concreto e coberturas asfálticas têm características termais previsíveis, com base em como eles seletivamente absorvem energia solar nos comprimentos de onda curtos e radiam energia infravermelha termal (JENSEN, 2009, p.251).

A temperatura cinética (verdadeira) da maior parte dos objetos da superfície terrestre se correlaciona positivamente bem com a temperatura radiante (aparente) registrada pelos sensores na faixa termal, formando o fundamento da medição (indireta) da temperatura cinética por meio do sensoriamento remoto termal. Não obstante, há que se considerar a questão da emissividade dos 
objetos, que por não se constituírem em elementos com perfeita emissão de radiação, como os corpos negros, possuem níveis distintos de emissividade, provocando, consequentemente, diferentes níveis de correlações entre as temperaturas cinéticas e as temperaturas aparentes registradas em determinadas cenas pelos sensores (JENSEN, 2009).

A tabela 1 mostra as taxas de emissividade de alguns elementos importantes da paisagem:

Tabela 1: Emissividade de diferentes elementos em relação a um corpo negro.

\begin{tabular}{cc}
\hline Elemento & Emissividade em relação a um corpo negro \\
\hline Água & $0,92-0,98$ \\
Concreto & $0,71-0,92$ \\
Asfalto & 0,95 \\
Solo & $0,90-0,95$ \\
Vegetação & $0,96-0,98$ \\
Grama & 0,97 \\
Metais e aço & $0,16-0,70$ \\
\hline
\end{tabular}

Fonte: adaptado de Jensen (2009, p. 260).

O impacto das distintas emissividades de alvos na interpretação de uma imagem termal é facilmente percebido ao se considerar que os elementos da tabela 1 irão apresentar temperaturas radiantes diferentes, mesmo que possuam a mesma temperatura cinética. Isso significa que a intepretação de uma imagem termal não se constitui em atividade tão simples, havendo que se considerar as variáveis relacionadas à emissividade; e para tornar a questão mais complexa, há também a atuação da atmosfera na emissão, atenuação e espalhamento atmosférico da radiância que chega ao sensor (GRONDONA; ROLIM, 2016).

Existem modelos para a correção dos efeitos da atmosfera e para estimativas de diferentes emissividades de materiais; todavia, ao comentarem sobre o uso de modelos no estudo do ambiente urbano, com essas finalidade, Voogt e Oke (2003) reconheceram que tais correções podem ser relativamente grosseiras, sendo desejável a melhoria delas, conforme o aumento da compreensão do comportamento da radiação urbana. Isso significa que o uso de modelos de correção, em si, pode não ser o suficiente para a obtenção de resultados completamente precisos. Grondona e Rolim (2016), por exemplo, apontaram a utilidade de se fazer a correção atmosférica quando possível, especialmente em ambientes úmidos; porém, observaram que para tal procedimento, são necessários dados auxiliares nem sempre disponíveis, indicando que o uso de modelos atmosféricos não condizentes com a área de estudo, por sua vez, pode representar mais um problema do que uma solução.

Certamente, para aplicações que necessitem quantificar da forma mais precisa possível as temperaturas radiantes e cinéticas, os modelos de correção atmosférica e de abordagem das distintas emissividades, utilizados de forma correta, devem estimar resultados mais exatos, todavia, existem 
aplicações nas quais tal nível de precisão pode não ser um requisito tão fundamental, desde que o analista esteja ciente dessas questões no momento da interpretação das imagens. No caso de uma área restrita, como a do presente estudo, e de um dia específico, por exemplo, o efeito atmosférico deverá atuar de forma semelhante em toda a área, o que minimiza seu ruído para efeito de comparação dos distintos valores dos pixels da imagem, que deverão ser atribuídos às diferenças no comportamento espectral dos alvos. Para fins de análise dos valores em si, entretanto, não se tem como escapar da condição de que serão apenas aproximações, contudo, úteis.

Embora, como lembrado por Voogt e Oke (2003), o uso do sensoriamento remoto para a obtenção das temperaturas de superfície se constitua em forma de medição indireta, com as distintas emissividades dos alvos e a atmosfera interferindo nas medições, como já abordado; Costa, Silva e Peres (2010) observaram corretamente que ele oferece a possibilidade única de apreensão espacial das temperaturas em diferentes escalas. Conforme Barros e Lombardo (2016) ele é a melhor opção para se estudar as temperaturas de grandes áreas. Assim, mesmo lidando com valores aproximados em variados níveis, o ganho de conhecimento em relação aos padrões espaciais da temperatura traz um acréscimo importante ao conhecimento ambiental.

É importante lembrar, por fim, que Matson et al. (1978) foi quem deu início aos estudos do fenômeno conhecido como ilhas de calor por meio do uso do espectro termal de sensores remotos. Tal fenômeno é relevante, pois se apresenta como um importante exemplo da constituição de diferentes padrões espaciais de temperaturas, induzidos pela intervenção antrópica no meio, captáveis pelo uso do sensoriamento remoto.

\section{RESULTADOS E DISCUSSÃO}

Inicia-se esta apresentação dos resultados com uma avaliação da carta-imagem (Figura 2). Para destacar as diferenças entre as superfícies com coberturas vegetais de diferentes portes e densidades, bem como entre elas e as superfícies com outros tipos de uso da terra (urbana, reservatórios e cursos de água), bastou a utilização da banda 5, da cena Landsat-8, no canal vermelho. Ao se evitar usar razões de bandas, muito comum nos estudos sobre as vegetações, preservou-se as informações texturais das imagens, importantes para a avaliação dos tipos de uso da terra; as coberturas vegetais ficaram destacadas pelas diferentes tonalidades de vermelho, graças ao comportamento espectral da vegetação no intervalo do infravermelho próximo, após o red edge; ocorre que nessa faixa espectral a reflectância da vegetação se correlaciona positivamente com o índice de área foliar, sendo tanto maior quanto esta (JESEN, 2009).

$\mathrm{Na}$ composição colorida falsa-cor em questão, percebe-se facilmente que a maior parte do município de Jacareí é destituída de coberturas densas de vegetação arbórea (exemplificadas na 
imagem pela área 1), predominando a vegetação herbácea (exemplificadas na imagem pela área 2). Há ainda importantes corpos de água ao norte e sudeste do município (exemplificados pela área 3), além da grande área de mancha urbana (exemplificada pela área 4). Assim, pode-se classificar os usos da terra no município, para a escala de análise em questão, em 4 grandes tipos, a saber: I) coberturas arbóreas (cerca de 15,12\% da área); II) coberturas herbáceas - frequentemente utilizadas para pastos (aproximadamente 67,48\%); III) corpos de água, como rios e represas (por volta de 4,94\%); IV) manchas urbanas e infraestruturas, como estradas (chegando próximo de 12.46\%).

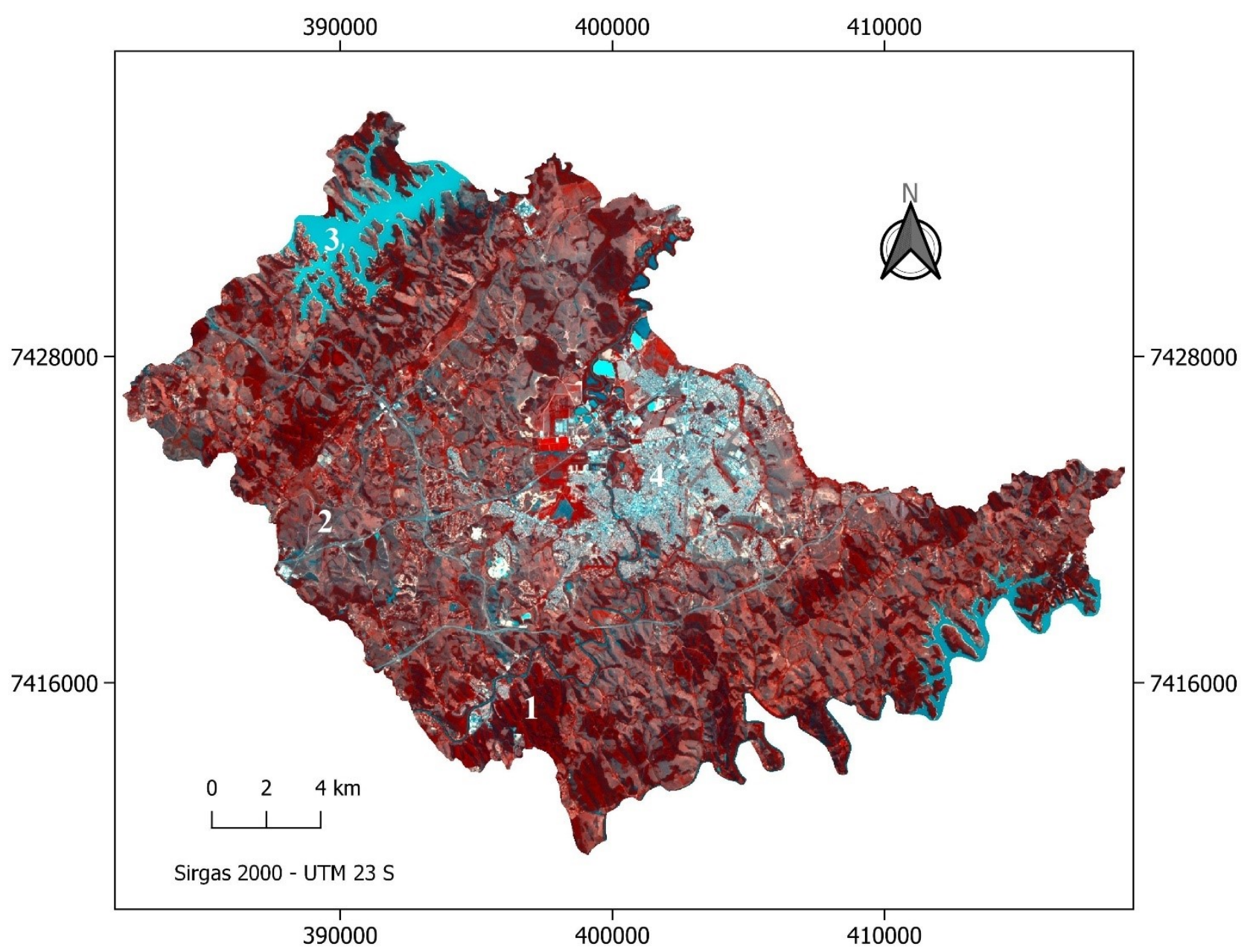

Figura 2 - Carta-imagem falsa-cor do município de Jacareí com os principais usos da terra. Fonte: elaborado pelo autor a partir de cena Landsat-8.

A figura 3 mostra o mapa de uso da terra para o município, gerado por classificação supervisionada sobre a composição colorida já apresentada; foram experimentados na pesquisa vários métodos de classificação supervisionada para as mesmas áreas de amostragem e o Winner takes all, ao presente juízo, foi o que apresentou os melhores resultados. 


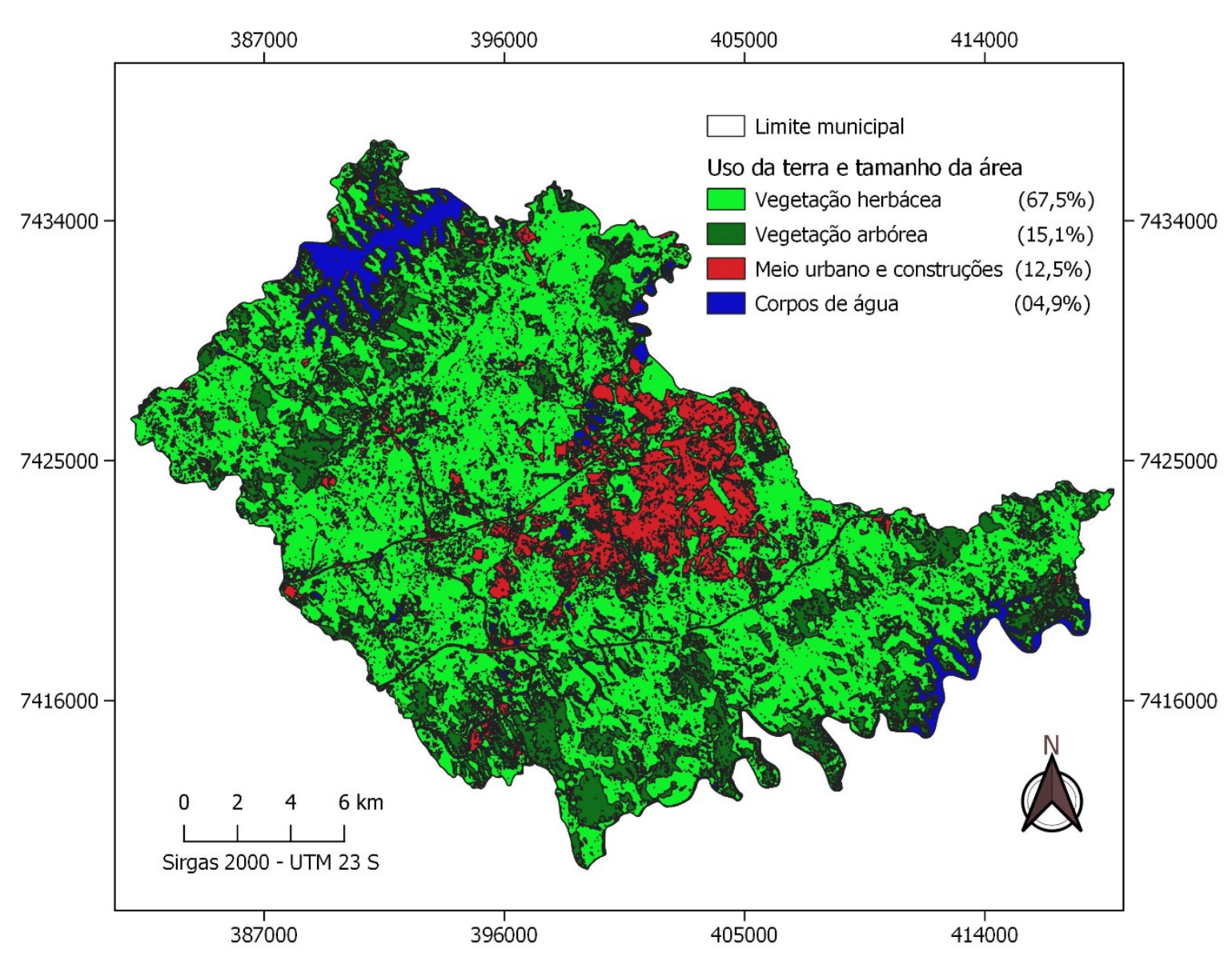

Figura 3 - Mapa de uso da terra do município de Jacareí. Fonte: elaborado pelo autor a partir de cena Landsat-8.

Ao se abordar a questão do uso da terra, torna-se relevante considerar as características demográficas do município. Ele contava com uma população de aproximadamente 211.214 habitantes em 2010, com crescimento populacional estimado de $11,46 \%$ nos últimos 10 anos, o que a fez passar para algo em torno de 235.416 habitantes em 2020, distribuídos em uma área aproximada de $464 \mathrm{~km}^{2}$ (IBGE, 2020). Dessa forma, é evidente que o município passa, neste momento, por um processo de expansão intensa de sua mancha urbana, sendo importante o planejamento do seu desenvolvimento urbano no que se refere aos fatores ambientais.

$\mathrm{Na}$ figura 4, finalmente, é possível verificar a distribuição das temperaturas superficiais aparentes do município para a cena e a data em questão. Antes de analisá-lo, contudo, é interessante apontar que a temperatura média do ar para o dia $06 / 10 / 2020$ foi de $24{ }^{\circ} \mathrm{C}$, sendo a máxima de $29^{\circ} \mathrm{C}$ e a mínima de $19{ }^{\circ} \mathrm{C}$, conforme dados da estação de medição presente no município (AGRITEMPO, 2020). Infelizmente, não foram encontrados dados de temperatura atmosférica específica, pelo menos para cada hora do dia, o que teria permitido a comparação da temperatura do ar no mesmo horário aproximado de aquisição da cena Landsat- 8 utilizada. De toda forma, conforme as estatísticas extraídas da imagem termal, as temperaturas de superfície para o dia e horário da imagem foram: 
mínima de $23,6^{\circ} \mathrm{C}$, máxima de $40,4{ }^{\circ} \mathrm{C}$ e média de $30{ }^{\circ} \mathrm{C}$. A maior parte do município, entretanto, apresentou temperaturas estimadas de superfície entre $26^{\circ} \mathrm{C}$ e $34,9^{\circ} \mathrm{C}$.

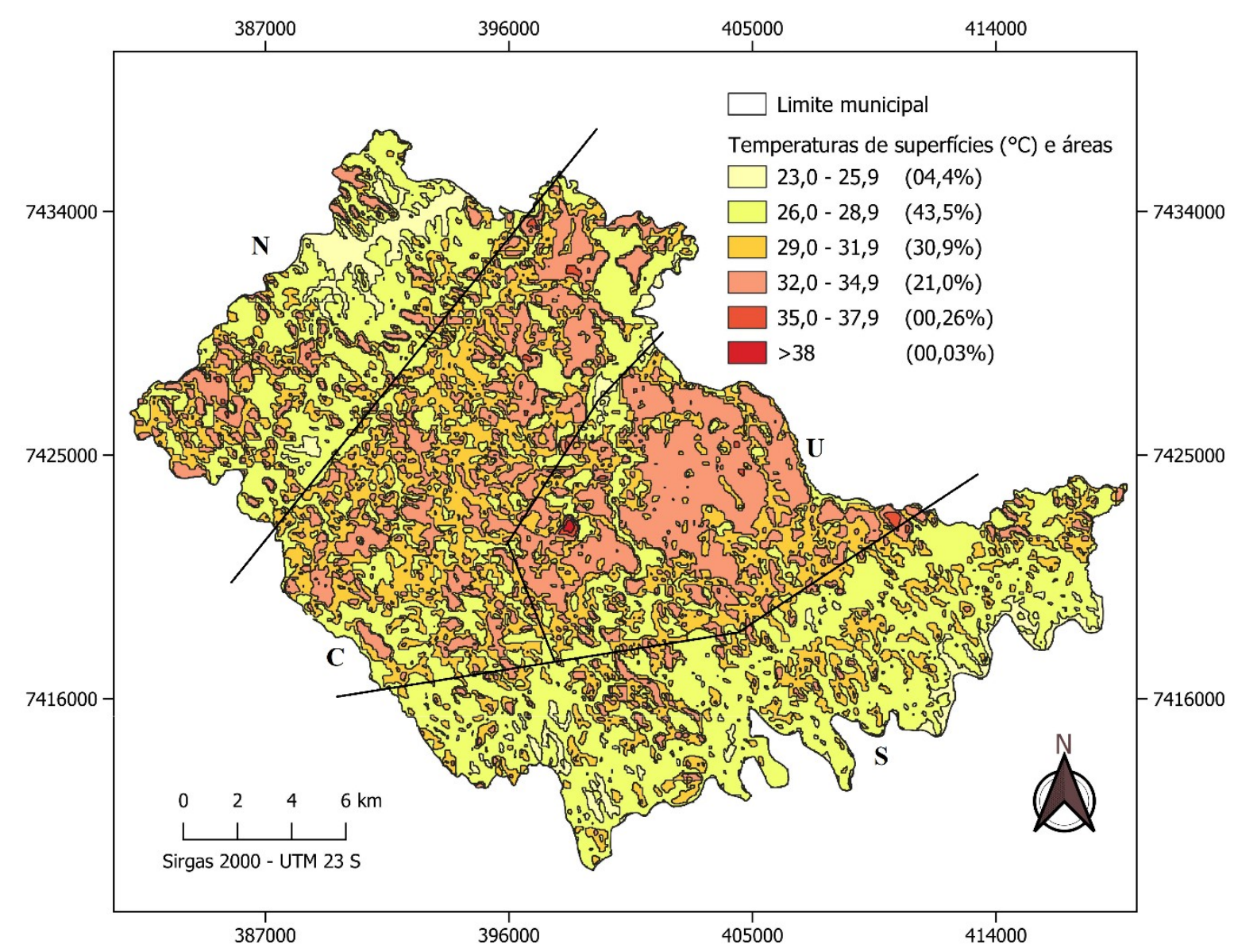

Figura 4 - Mapa de Temperatura Superficial do Município de Jacareí.

Fonte: elaborado pelo autor a partir de cena Landsat-8.

Observando mais atentamente o padrão espacial de temperatura superficial, percebe-se que nas extremidades do município (identificadas pelas letras $\mathrm{N}$ e $\mathrm{S}$ ) a ocorrência de temperaturas relativamente mais baixas é visivelmente mais preponderante; tratam-se de áreas com a presença de importantes corpos de água e altitudes mais elevadas; nelas ocorrem também fragmentos vegetais de maior porte e densidade, bem como ausência de núcleos urbanos de tamanhos significativos, fatores que podem explicar, pelo menos parcialmente, este resultado. As áreas mais centrais (C), por sua vez, possuem intensa variabilidade de temperaturas mais altas e baixas, com poucos fragmentos vegetais de maior porte e densidade, ou seja, a presença das gramíneas se faz amplamente predominante e as altitudes são sensivelmente inferiores em relação às área $\mathrm{N}$ e $\mathrm{S}$, fatores que também ajudam a explicar as características térmicas da superfície; mas é necessário reconhecer que a complexidade no padrão térmico espacial apresentada por esta área é de certa forma intrigante, pois destoa da relativa monotonia do tipo de uso da terra ali presente; um estudo multitemporal, talvez, permitiria verificar 
se a ocorrência de queimadas naquele dia poderia ser um dos elementos responsáveis pelo padrão apresentado.

Por fim, a região centro-leste (U) possui ampla participação de superfícies urbanizadas, sobre as quais as temperaturas superficiais mais elevadas do município são amplamente predominantes; é também onde vive a maior parte da população, sendo igualmente importante salientar que se trata das áreas de relevo de menor altitude (quanto às características do relevo municipal, o presente autor realizou estudo sobre os seus aspectos, contudo, ele ainda está em processo de publicação. As áreas $\mathrm{N}$ e S são correspondentes, aproximadamente, às unidades do Planalto Atlântico que ocorrem sobre terrenos geologicamente mais antigos e elevados. A área C possui altitudes menores, trata-se de planalto em terrenos sedimentares do graben da Bacia de Taubaté. A área U, por fim, possui as altitudes mais modestas, sendo formada basicamente pela planície do rio Paraíba do Sul. As diferenças altimétricas do relevo municipal ultrapassam os 200 metros de altitude, o que é suficiente para exercer alguma influência sobre as diferenças de temperatura).

Cabe destacar que os traços feitos no mapa para delimitar as unidades $\mathrm{N}, \mathrm{S}, \mathrm{C}$ e U foram arbitrários e apoximativos, com o objetivo de auxiliar na avaliação da imagem e não de traças limites absolutos de regiões térmicas superficiais.

Algo que se apresenta com definitiva clareza nos padrões espaciais de temperatura de superfície da figura 4 é o contraste de temperaturas entre as áreas com vegetação arbórea mais densa e as áreas urbanas; e mesmo dentro destas, a diferença nas temperaturas de áreas com significativa presença de vegetação arbórea se faz presente em relação à vizinhança urbanizada. Nesse sentido, a figura 5 apresenta as temperaturas superficiais estimadas de um núcleo urbano do município de Jacareí, relativamente afastado da área urbana principal, e cercado por superfícies com gramíneas e vegetação arbórea. Percebe-se claramente que o pequeno núcleo urbano possui temperaturas superficiais relativamente mais elevadas, em relação ao seu entorno; a diferença térmica superficial entre essas áreas chegou, para a cena em análise, a algo próximo de $8.9^{\circ} \mathrm{C}$.

Este caso é importante, pois demonstra que para os impactos da urbanização sobre as temperaturas superficiais se fazerem presente não é necessária a constituição de manchas urbanas muito extensas, sendo importante, com isso, planejar a arboraziação, mesmo em pequenos núcleos urbanos, tendo em vista o conforto térmico de sua população. No caso de toda a área apresentada, ela possui extensão inferior a $1 \mathrm{~km}^{2}$. 


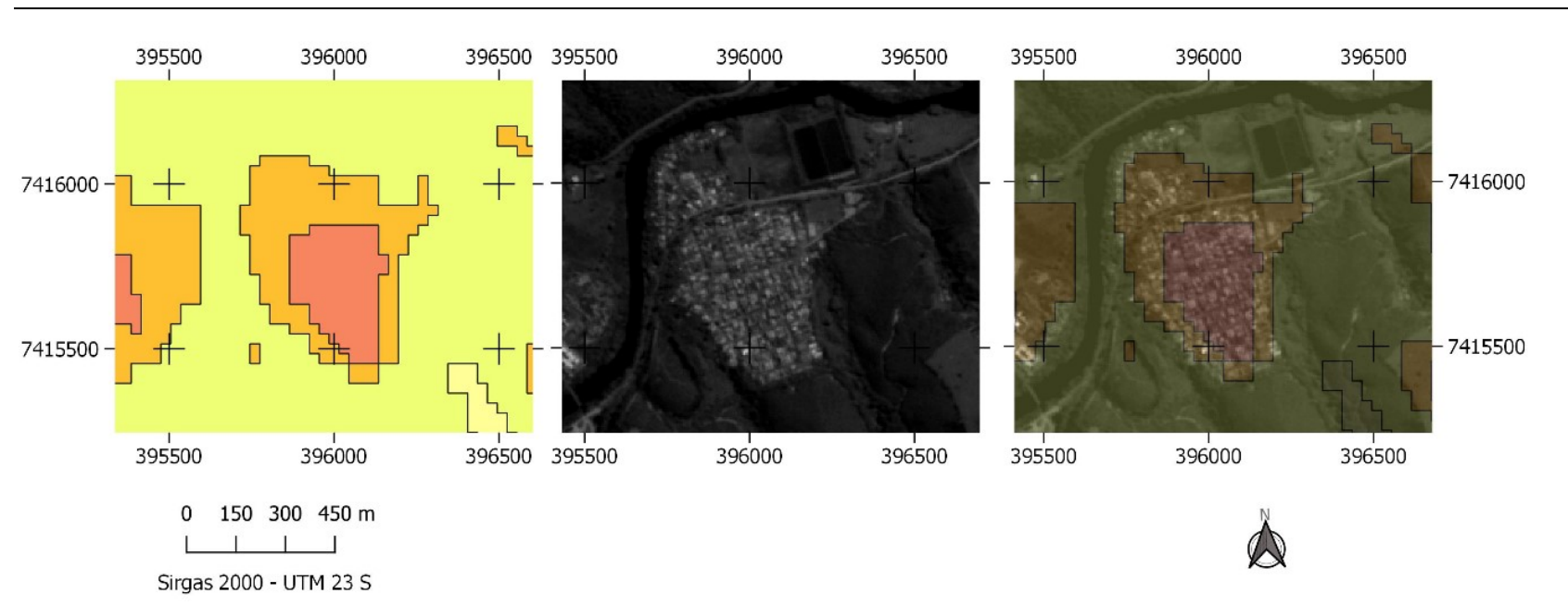

Figura 5 - Comparação das temperaturas superficiais com o uso da terra. Fonte: elaborado pelo autor a partir de cenas Landsat- 8 e Cbers-4.

A figura 6 exemplifica uma situação completamente oposta à anterior. Trata-se de área amplamente urbanizada com uma "ilha" de vegetação arbórea e densa. Percebe-se que a área de vegetação apresenta temperaturas superficiais relativamente mais baixas em relação ao seu entorno urbanizado. A diferença de temperatura também pode chegar à aproximadamente $8.9^{\circ} \mathrm{C}$ de diferença em relação à vizinhança urbanizada. Aqui, a tese que se confirma é de que áreas arborizadas não muito grandes já atuam na amenização da temperatura superficial urbana; neste caso, tem-se área inferior à $1 \mathrm{~km}^{2}$. É importante ressaltar, considerando as distintas emissividades de elementos como a vegetação, o concreto e o asfalto (algo já mostrado na tabela 1), que as diferenças entre as temperaturas superficiais possivelmente sejam mais intensas, na realidade, ou seja, as superfícies urbanizadas podem apresentar temperaturas superficiais um pouco mais elevadas do que as registradas indiretamente pelos sensores, já que a emissividade do concreto e asfalto é inferior à da vegetação.

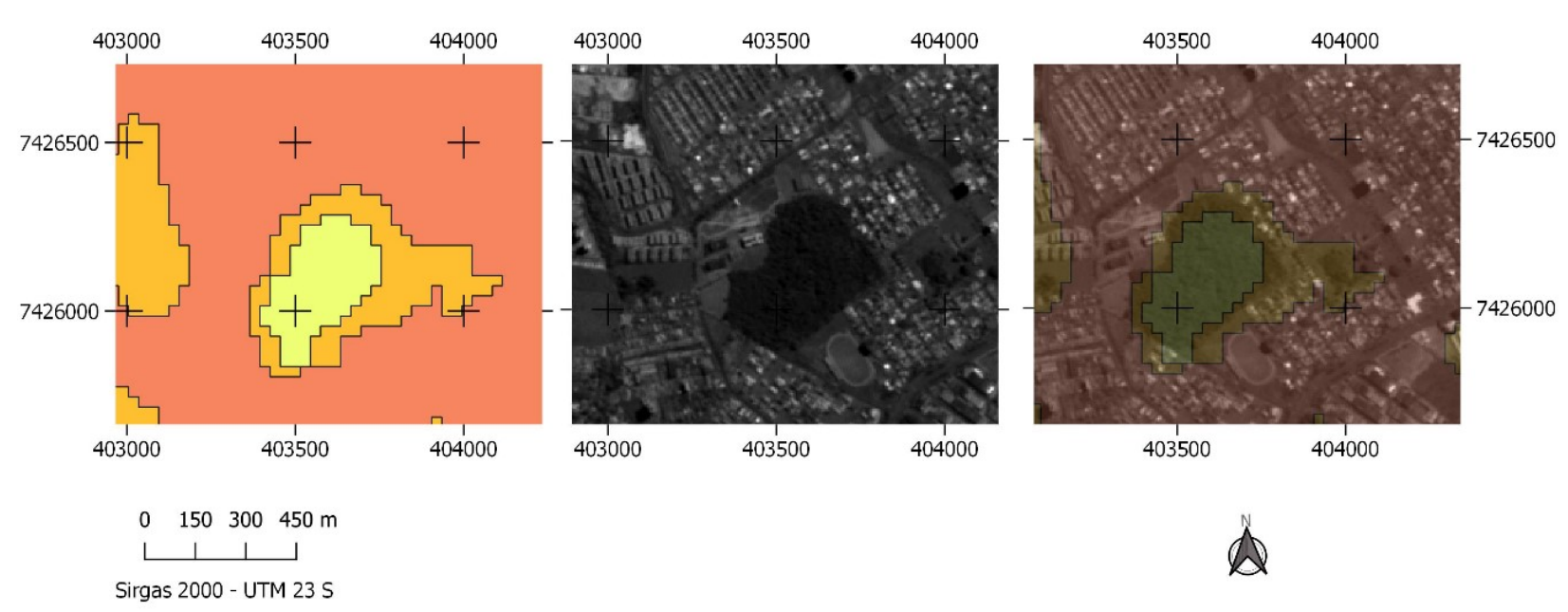

Figura 6 - Comparação das temperaturas superficiais com o uso da terra.

Fonte: elaborado pelo autor a partir de cenas Landsat-8 e Cbers-4. 
Essas diferenças empíricas de temperaturas superficiais entre as áreas urbanas, mais elevadas, e as áreas com vegetação arbórea, relativamente mais amenas, não se constituem em novidade ao serem contrapostas com a literatura científica; elas configuram o conceito já exposto de ilha de calor de superfície urbana. Resta considerar, entretanto, que as temperaturas das superfícies são um dos fatores primordiais da climatologia urbana, pois atuam na modulação da temperatura do ar nas camadas inferiores da atmosfera. Assim, enquanto as ilhas de calor urbanas costumam ser estudadas por meio de estações fixas ou móveis de medição da temperatura do ar, o sensoriamento remoto termal permite o estudo das ilhas de calor de superfície que vão impactar na formação daquelas (VOOGT; OKE, 2003).

Como existe relação entre as temperaturas do ar e as da superfície, o fenômeno da ilha de calor também pode ser estudado a partir das temperaturas da superfície, com a observação de que esta pode ser mais elevada e variante em relação à temperatura do ar, pois as diferenças na composição da superfície são maiores do que as da atmosfera. É importante observar que as diferenças mais significativas de temperaturas na atmosfera e na superfície ocorrem em períodos distintos; enquanto as maiores diferenças das temperaturas do ar ocorrem pela noite, as da superfície acontecem ao meio dia, já que estas ganham e perdem calor mais velozmente (IMHOFF et al., 2010). A interação entre as temperaturas do ar e da superfície pode ser facilmente reconhecida na medida em que se compreende o fato de a superfície, como as de concreto e asfalto do ambiente urbano, transferir seu calor, armazenado ao longo do dia, para a atmosfera, durante a noite (GALLO et al., 1993). Assim, é possível considerar as ilhas de calor de superfície como uma das dimensões de um fenômeno maior de alteração do microclima urbano que configura a ilha de calor. Conforme Oke (1987), a formação das ilhas de calor representa o caso mais evidente dos efeitos das alterações antrópicas sobre o clima. Para Voogt e Oke (2003), pode-se abordar as ilhas de calor para distintas camadas atmosféricas e superfícies, embora seja fundamental conhecer as diferenças em seus mecanismos.

Para o caso de Jacareí, a configuração espacial de sua mancha urbana principal não está completamente rodeada por densa vegetação arbórea; o comportamento termal das superfícies herbáceas mais complexas do setor $\mathrm{C}$, por sua vez, que apresenta várias ocorrências de temperaturas mais elevadas, acaba camuflando o aspecto de ilha de calor urbana superficial da mancha urbana principal, mas ela ocorre (seria interessante mais pesquisas para entender esse comportamento termal das superfícies do setor C, não tão associados à presença de superfícies urbanas quanto a do setor U), bastando comparar o comportamento termal do setor $\mathrm{U}$ com os setores $\mathrm{S}$ e $\mathrm{N}$, além de observar os exemplos específicos representados pelos casos das figuras 5 e 6 para confirmar a sua presença no município.

Assim, se as superfícies urbanas do município não são as únicas a apresentarem as maiores temperaturas superficiais, elas estão entre as que apresentam as temperaturas superficiais mais 
elevadas, em nítido contraste com as áreas de significativa presença de vegetação arbórea e corpos de água; aliás, quando as áreas de vegetação arbórea mais densa se encontram dentro dos setores urbanizados, como demonstrado na figura 6, ocorre o que se tomará a liberdade de denominar como ilha de amenização superficial urbana, ou seja, espaços dentro das áreas urbanas com temperaturas superficiais mais amenas em relação ao seu redor. Considerando que tais superfícies modulam a temperatura da baixa atmosfera, é de se esperar que amenizem também a temperatura atmosférica local e a temperatura dentro das construções. Isso indica que cidades mais arborizadas podem melhorar o conforto térmico de sua população nos dias mais quentes.

Nesse contexto, é relevante considerar o estudo sistemático de Bowler et al., (2010) sobre as evidências empíricas existentes a respeito dos impactos da vegetação na temperatura atmosférica das cidades. As principais conclusões às quais os autores chegaram foram: a presença de áreas verdes, como os parques, ameniza a temperatura do ambiente, com estimativas indicando a média de $1^{\circ} \mathrm{C}$ de diferença em relação às áreas não verdes; essa capacidade de amenização está relacionada com o tamanho da área verde (no caso, os parques); alguns estudos apontam que o efeito de amenização vai além dos limites dos parques; mesmo árvores individuais podem amenizar a temperatura abaixo de suas copas.

É evidente que as áreas verdes contribuem decisivamente para a diminuição das temperaturas das superfícies inferiores devido à sombra produzida sobre essas superfícies. Oke et al., (2017), por sinal, afirmaram que as árvores atuam na modificação da temperatura do ar e sua umidade não somente de forma direta, por meio de suas copas, mas também de forma indireta, por conta das sombras que projetam sobre a superfície; o impacto das árvores sobre o microclima, todavia, varia conforme vários fatores, tais como: a arquitetura das copas, as densidades das folhagens, as espécies, suas idades e condição de saúde.

Os dados empíricos obtidos, contrapostos à teoria, demonstram a necessidade de o município de Jacareí, em franco processo de crescimento demográfico e urbano, promover a adoção de políticas públicas consistentes de arborização dos espaços públicos e criação de parques, a fim de melhorar os impactos térmicos da sua urbanização, criando maior conforto e qualidade de vida para os seus habitantes.

\section{CONCLUSÕES}

O sensoriamento remoto termal permite estimar, indiretamente, a temperatura cinética das superfícies a partir de suas temperaturas irradiadas. As temperaturas superficiais, por sua vez, modulam as características das temperaturas da baixa atmosfera e ambas atuam na sensação térmica dos seres vivos. Nesse contexto, o presente estudo abordou o município de Jacareí, a fim de 
diagnosticar suas características térmicas para determinada cena do Landsat-8, em dia específico, com o auxílio técnico das geotecnologias (geoprocessamento e sensoriamento remoto).

Foram identificadas quatro grandes áreas térmicas do município, classificadas como setores

N, S, C e U. Nas duas primeiras, as temperaturas superficiais foram relativamente mais baixas (apesar da existência de zonas localizadas mais quentes); algo que era de se esperar, ao se considerar que nelas estão presentes grandes reservatórios de água, áreas de vegetação arbórea mais densas e maiores altitudes do relevo. O setor $\mathrm{C}$ é uma área mais complexa, pois apresenta uma mistura muito grande das diferentes classes de temperatura superficial, algo intrigante; nela predomina a cobertura vegetal herbácea que aparenta ter um comportamento térmico mais complexo. O Setor U, por fim, é dominado por áreas urbanas, que estão entre as superfícies de maior temperatura do município, configurando o fenômeno de ilha de calor superficial urbana.

Os resultados indicam que o município de Jacareí, em franco processo de crescimento demográfico e urbano necessita de planos e políticas públicas voltadas ao planejamento do crescimento de sua mancha urbana, no sentido de criar e/ou manter espaços verdes que favoreçam o conforto térmico da população, gerado pela presença da vegetação arbórea em quantidade significativa. Foram demonstrados exemplos empíricos no município de que essa presença da vegetação propicia o benefício do conforto térmico superficial, essencial para a vivência em um ambiente urbano com qualidade ambiental.

\section{REFERÊNCIAS}

AGRITEMPO. Sistema de monitoramento agrometeorológico. 2020. Disponível em: $<$ https://www.agritempo.gov.br/agritempo/jsp/PesquisaClima/index.jsp?siglaUF=SP $>$. Acesso em: 08 nov. 2020.

BARROS, H. R.; LOMBARDO, M. A. A ilha de calor urbana e o uso e cobertura do solo em São Paulo-SP. Geousp - Espaço e Tempo (Online), v. 20, n. 1, p. 160-177, 2016.

BOWLER, D. E.; BUYUNG-ALI, L.; KNIGHT, M.; PULLIN, A. S. Urban greening to cool towns and cities: a systematic review of the empirical evidence. Landscape and urban planning, n. 97, p. 147-155, 2010.

BRASIL. Constituição da República Federativa do Brasil. 1988. Disponível em: < http://www.planalto.gov.br/ccivil_03/constituicao/constituicao.htm>. Acesso em: 10 nov. 2020.

COELhO, A. L. N.; CORREA, W. S. C. Temperatura de superfície celsius do sensor TIRS/LANDSAT-8: metodologia e aplicações. Rev. Geogr. Acadêmica, v. 7, n. 1, p. 31-45, 2013.

DA COSTA, D. F.; SILVA, H. R.; PERES, L. F. Identificação de ilhas de calor na área urbana de Ilha Solteira - SP através da utilização de geotecnologias. Eng. Agríc., Jaboticabal, v. 30, n. 5, p. 974-985, 2010. 
IBGE. Malha municipal. 2019. Disponível em: $<$ https://www.ibge.gov.br/geociencias/organizacaodo-territorio/malhas-territoriais/15774-malhas.html? $=\& \mathrm{t}=$ downloads $>$. Acesso em: 01 nov. 2020.

IBGE. Cidades@. 2020. Disponível em: < https://cidades.ibge.gov.br/brasil/sp/jacarei/panorama>. Acesso em: 01 nov. 2020.

CBERS-4 PAN - INSTITUTO NACIONAL DE PESQUISAS ESPACIAIS. Imagens de Satélite. 2018. Disponível em: <http://www.dgi.inpe.br/catalogo/ > Acesso em: 01 nov. 2020.

FITZ, P. R. Geoprocessamento sem complicação. 1. ed. São Paulo: Oficina de Texto, 2008. 249p.

GALLO, K. P.; McNAB, A.L.; KARL, T. R.; BROWN, J. F.; HOOD, J. J.; TARPLEY, J. D. The use of NOAA AVHRR data for assessment of the urban heat island effect. Journal of applied meteorology, v. 32, p. 899-908, 1993.

GRONDONA, A.; ROLIM, S. B. A. Separação de temperatura e emissividade a partir de imagens do infravermelho termal: análise de suas aplicações/restrições. Boletim de ciências geodésicas, Curitiba, v. 22, n. 1, p. 16-34, 2016.

IMHOFF, M. L.; ZHANG, P.; WOLFE, R. E.; BOUNOUA, L. Remote sensing of the urban heat island effect across biomes in the continental USA. Remote Sensing of Environment, v. .114, n. 3, p. 504-513, 2010.

JENSEN, J. R. Sensoriamento remoto do ambiente: uma perspectiva em recursos terrestres. 1. ed. São José dos Campos: Parêntese Editora, 2009. 672p.

LANDSAT OLI/TIRS 8: U.S. Geological Survey, 2020. Imagem de Satélite. Disponível em: < https://earthexplorer.usgs.gov/ > Acesso em: 01 nov. 2020.

MATSON, M.; MCCLAIN, E. P.; McGINNIS JR., D. F.; PRITCHARD, J. A. Satellite Detection of Heat Islands. Monthly Weather Review, v. 106, n. 2, p. 1725-1734, 1978.

NOVO, E. M. L. M. Sensoriamento remoto: princípios e aplicações. 1. ed. São Paulo: Editora Edgard Blücher, 1989. 389p.

OKE, T. R. Boundary layer climates. 2 ed. London/New York: Routledge, 1987. 464p.

OKE, T. R.; MILLS, G.; CHRISTEN, A.; VOOGT, J. A. Urban climates. Cambridge: Cambridge University Press, 2017.

SILVA, M. M. Técnicas cartográficas aplicadas ao zoneamento ambiental: município de Jacareí - SP. 2002. 102 f. Dissertação (Mestrado em Geociências) - Dissertação de mestrado - Instituto de Geociências Exatas, Universidade Estadual Paulista, Rio Claro, 2002.

VOOGT, J. A.; OKE, T. R. Thermal remote sensing of urban climates. Remote Sensing of Environment, n. 86, p. 370-384, 2003.

ZAIDAN, R. T. Geoprocessamento conceitos e definições. Revista de Geografia. Juiz de Fora, v. 7, n. 2, p. 195-201, 2017. 